\title{
Influência da substituição da proteína animal na qualidade da água em viveiros do tambaqui Colossoma macropomum (Cuvier, 1818)
}

Campos Sousa, P.H.; Souza Santos, M.de L.; Lobão Souza, R.A.; dos Santos, V.A.; Machado Santos, R. e de Lima Saraiva, A.L.

Instituto Socioambiental e dois Recursos Hidricos - ISARH. Universidade Federal Rural da Amazônia. Universidade Federal Rural da Amazônia.

PalAVRAS CHAVE ADICIONAIS

Massa de mandioca.

Oxigênio dissolvido.

Piscicultura sustentável.

Viveiros de maré.

\section{RESUMO}

O crescimento da aquicultura como agroindústria e a intensificação de estratégias de produção condicionaram a busca por ingredientes de alta qualidade, por exemplo, a ração que é o insumo que representa o maior percentual individual de despesas. Na região amazônica o cultivo extensivo é visto como uma alternativa para famílias de baixa renda. Com isso, o enfoque do presente artigo é avaliar a qualidade da água em viveiros de cultivo de tambaqui, submetidos em três tratamentos de rações com substituiçães percentuais da ração comercial por uma proteína vegetal. O experimento foi desenvolvido em 182 dias em área de várzea na Comunidade de Estirão do Mamão em 2010, localizada no município de Moju - PA. Foram utilizados 500 alevinos estocados em 13 viveiros escavados com área de $50 \mathrm{~m} 2$, abastecidos individualmente com água proveniente do rio Moju, conforme o nível da maré com densidades de 1 peixe/m2. No decorrer do experimento, os peixes foram alimentados conforme os três tratamentos: I) $70 \%$ de ração comercial $+30 \%$ de massa de mandioca; II) $50 \%$ de ração comercial + $50 \%$ de massa de mandioca; III) $30 \%$ de ração comercial + $70 \%$ de massa de mandioca e o Testemunho com $100 \%$ ração comercial. Os tratamentos não tiveram uma influência no crescimento do peixe e na qualidade da água, no qual a variável com maior destaque foi à sazonalidade. Os parâmetros físicos e químicos, como a temperatura, o oxigênio dissolvido, $\mathrm{CE}$ e o pH tiveram uma relação com o desenvolvimento dos peixes. Os compostos nitrogenados não tiveram nem uma modificação ao longo do desenvolvimento e não influenciaram no desenvolvimento do peixe.

\section{Influence of animal protein substitution on water quality in tambaqui Colosoma macropomum nurseries (Cuvier, 1818)}

\begin{abstract}
SUMMARY
The growth of aquaculture as agribusiness and the intensification of production strategies have conditioned the search for high quality ingredients, for example, the feed that is the input that represents the highest individual percentage of expenses. In the Amazon region, extensive farming is seen as an alternative for low-income families. Therefore, the focus of the present article is to evaluate the water quality in tambaqui nurseries submitted to three treatments of rations with percentage substitutions of the commercial ration by a vegetal protein. The experiment was developed in 182 days in lowland area in the community of Estirão do Mamão in 2010, located in the municipality of Moju - PA. It was used 500 fish stocked in 13 nurseries excavated with an area of $50 \mathrm{~m} 2$, supplied individually with water from the Moju river, according to the level of the tide with densities of $1 \mathrm{fish} / \mathrm{m} 2$. During the experiment, the fish were fed according to the three treatments: II) $70 \%$ commercial feed $+30 \%$ cassava mass; II) $50 \%$ commercial ration $+50 \%$ cassava mass; III) $30 \%$ of commercial ration $+70 \%$ of manioc mass and the Testimony with $100 \%$ commercial ration. The treatments had no influence on fish growth and water quality, in which the most prominent variable was seasonality. Physical and chemical parameters, such as temperature, dissolved oxygen, EC and pH had a relationship with fish development. The nitrogen compounds did not have a modification throughout the development and did not influence the development of the fish.
\end{abstract}

\section{INTRODUÇÃO}

O crescimento da aquicultura como agroindústria e a intensificação de estratégias de produção condicionaram a busca por ingredientes de alta qualidade que permitam a formulação e o processamento de dietas nutricionalmente completas e economicamente viáveis, maximizando a produção de pescado e minimizando o impacto ambiental de sistemas de produção (Cyrino et al., 2010).
Na piscicultura, a ração é o insumo que representa o maior percentual individual de despesas, representando de 60 a 70\% dos custos de produção, no qual a proteína é a fração que adiciona o maior valor (Sá \& Fracalossi, 2002; Vieira et al., 2005), desta forma a necessidade de adotar medidas onde possa reduzir os custos por meio adequado de manejo alimentar com a adição de novos ingredientes. Com isso, a realização de estudos com utilização de fontes protéicas de origem vegetal na elaboração de rações para peixes comerciais 
tem se tornado mais frequente (Soares et al., 2000; Soares et al., 2001; Galdioli et al., 2002; Silva et al., 2003).

A manutenção da qualidade de água em viveiros de piscicultura é requisito básico para o sucesso econômico do sistema produtivo e pode ser influenciada por vários fatores, dentre eles, a origem da fonte de abastecimento de água e o manejo alimentar (Pereira \& Mercante, 2005), de maneira que a qualidade da água não seja prejudicada ao colocar a ração e quando adicionado outros ingredientes na dieta dos peixes.

Na região amazônica o cultivo extensivo é visto como uma alternativa para famílias de baixa renda, pois as técnicas de manejo utilizadas são simples e pouco especializadas, o tambaqui é uma espécie que se adapta as condições de cultivo, sendo bastante utilizada em sistemas extensivos. Assim o cultivo de tambaqui, se transforma em uma atividade promissora para diminuir a sobrepesca dessa espécie nos rios amazônicos. Entretanto, a principal dificuldade encontrada na alimentação de animais aquáticos em cativeiro, é devido aos altos custos das rações comerciais, assim a busca por produtos agrícolas e florestais de baixo custo e regional como a mandioca (Manihot esculenta), são de total importância para a expansão da atividade píscicola no Estado do Pará (Santos et al., 2015).

Este artigo tem como enfoque avaliar a qualidade da água em viveiros de cultivo de tambaqui (Colossoma macropomum), os quais foram submetidos em três tratamentos de rações com substituições percentuais da ração comercial por uma proteína vegetal.

O Colossoma macropomum (Cuvier, 1818) é uma espécie natural da bacia amazônica, o qual possui um alto potencial de cultivo e grande importância econômica e social para as famílias ribeirinhas do Amazonas (Melo et al., 1998; Val et al., 2000). No entanto por apresentar características como rusticidade, alta produtividade e aceitar rações extrusadas e peletizadas, este onívoro tornou-se uma espécie chave em programas de criação no Brasil (Araújo-Lima \& Gomes, 2010).

\section{MATERIAL E MÉTODOS}

O experimento foi desenvolvido em 182 dias em área de várzea na Comunidade Estirão do Mamão em 2010, localizado no município de Moju - PA, situado entre os paralelos $2^{\circ} 12^{\prime} 43.44^{\prime \prime} \mathrm{S}$ à $2^{\circ} 12$ > 53,98" $\mathrm{S}$ e entre os meridianos $48^{\circ} 47^{\prime} 52,62^{\prime \prime} \mathrm{W}$ à $48^{\circ} 47^{\prime} 41,48^{\prime \prime} \mathrm{W}$ (Figura 1). Onde o experimento foi realizado nos meses de janeiro a julho abrangendo o período de maior ao menor índice pluviométrico respectivamente.

Os viveiros de $50 \mathrm{~m}^{2}$ receberam calagem de 1000 $\mathrm{Kg} / \mathrm{ha}$, que corresponde a $5 \mathrm{~kg}$ por viveiro, para correção do pH e medida profilática, após 24 horas, foi fertilizado com superfosfato simples $\mathrm{P}_{2} \mathrm{O}_{3}(16 \%)$ na quantidade de $18 \mathrm{~g} / \mathrm{m}^{3}$, perfazendo um total 900 gramas.

Foram utilizados 500 alevinos de tambaqui com peso médio total de $0,47 \pm 0,27 \mathrm{~g}$ e comprimento médio total 2,92 $\pm 0,58 \mathrm{~cm}$ provenientes de desova induzida do estado de Alagoas, e em seguida transportados em caixa de PVC (capacidade de 150L) com aeração constante até a comunidade Estirão do Mamão.
Os peixes foram aclimatados e estocados em treze (13) viveiros escavados com área de $50 \mathrm{~m}^{2}$ abastecidos individualmente com água proveniente do rio Moju, conforme o nível da maré. Todos os peixes foram povoados em densidades de 1 peixe $/ \mathrm{m}^{2}$. As medidas biométricas foram efetuadas mensalmente ao acaso com um número de indivíduos correspondendo a 30\% da quantidade total em cada viveiro seguido por (Bernardino \& Melo 1989).

Foram utilizados três tratamentos e quatro repetições com uma testemunha totalizando treze viveiros. No decorrer do experimento, os peixes foram alimentados conforme os três tratamentos abaixo:

Tratamento 1: 70\% de Ração comercial farelada + 30\% de massa de Mandioca;

Tratamento 2: $50 \%$ de Ração comercial farelada + $50 \%$ de massa de Mandioca;

Tratamento 3: 30\% de Ração comercial farelada + $70 \%$ de massa de Mandioca e o

\section{Controle com $100 \%$ de ração comercial farelada.}

A massa de mandioca branca foi lavada duas vezes, triturada e seca ao sol, para posteriormente ser utilizada como alimento alternativo aos peixes.

\section{MEDIÇÕES E ANÁLISES}

As coletas de águas superficiais foram realizadas a $50 \mathrm{~cm}$ de profundidade utilizando uma garrafa de Van Dorn em acrílico com capacidade de 5 litros, posteriormente acondicionados em frascos de polietileno esterilizados e armazenados em uma caixa térmica com gelo até a chegada no laboratório para posteriores análise com base nas recomendações da NBR 9898 especificadas em Von Sperling, 2007.

As análises laboratoriais dos nutrientes; nitrato $\left(\mathrm{NO}_{3}^{-} \mathrm{mg} . \mathrm{L}^{-1}\right)$, nitrito $\left(\mathrm{NO}_{2}^{-}-\mathrm{mg}\right.$. $\left.\mathrm{L}^{-1}\right)$ e amônia total $\left(\mathrm{NH}_{3} \mathrm{e} \mathrm{NH}_{4}{ }^{+}-\mathrm{mg}\right.$. L $\left.{ }^{-1}\right)$ foram realizadas utilizando-se uma sonda multiparâmetros colorimétrica Hanna 200.

\section{ANALISES ESTATÍSTICA}

Primeiramente os dados foram tabulados e realizada a estatística descritiva, em seguida foram submetidos ao teste de Shapiro-Wilk (normalidade) onde os

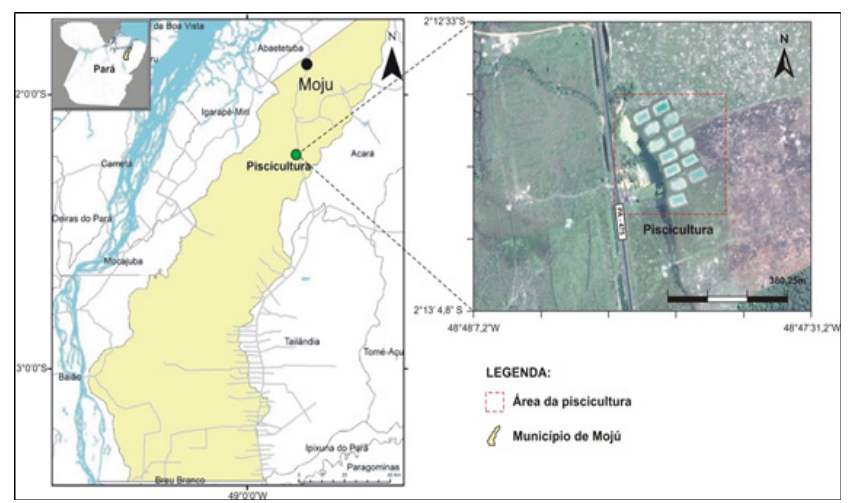

Figura 1. Mapa de localização dos viveiros experimentais, localizados na Comunidade do Estirão do Mamão, município de Moju-PA (Map of location of experimental nurseries, located in the Community of Estirão do Mamão, municipality of Moju-PA).. 
mesmos não apresentam normalidade, posteriormente realizou-se correlação não paramétrica de Spearman $(p<0,05)$, para verificar se houver correlação entres os parâmetros químicos e os tratamentos das rações com a massa de mandioca através dos dados zootécnicos. E por fim realizado uma análise de componente principal (Principal Component Analysis - PCA), para verificar se houve diferença nos parâmetros físico-químicos, sazonalidade e entre os tratamentos e o controle durante o experimento.

\section{RESULTADOS E DISCUSSÃO}

A temperatura da água nos viveiros oscilou de $29,20^{\circ} \mathrm{C}$ a $35,50^{\circ} \mathrm{C}$ (Tabela I), ambos no período chuvoso.

Esses valores podem ser explicados pelo fato da coleta ter sido realizada no horário da maior incidência solar, mesmo na temporada de altos índices pluviométricos da região e também pela ausência da vegetação nas margens dos viveiros e por ser um ambiente lêntico, o que permitiu o maior aquecimento da água, fato relatado também por (Arbeláez-Rojas et al.,2002) em um cultivo intensivo com tambaquis, em Manaus.

Através da Tabela I podemos observar que o valor da mediana da temperatura ficou dentro do limite estabelecido por (Val \& Honczaryk 1995; Kubitza, 2003), de 25 e $34^{\circ} \mathrm{C}$. Contudo, o máximo detectado ficou acima da faixa estabelecida pelos autores, porém, não prejudicou o desenvolvimento dos animais nos viveiros.

Trabalhos desenvolvidos para avaliar a temperatura da água durante a digestibilidade $\left(30,43\right.$ a $\left.32,62^{\circ} \mathrm{C}\right)$, nos efeitos da troca de águas em viveiros $\left(30,43\right.$ a $\left.32,62^{\circ} \mathrm{C}\right)$ e nos efeitos da suplementação da fitase na alimentação $(28,67$ a 29,03$)$ de tambaqui foram descritos Vidal Junior et al., 2004, Barroncas et al., 2015 e Mendonça et al., 2012, respectivamente, o que reforça ser a faixa boa de temperatura para a produção desses organismos. A correlação verificada entre a temperatura e o oxigênio dissolvido reforça que a troca de água necessária sempre ocorreu durante o horário de maior incidência solar (Tabela II).

De acordo com a Tabela I a condutividade elétrica oscilou de 8 a $135 \mu$ S.cm ${ }^{-1}$, ambos no período chuvoso. $\mathrm{O}$ valor mínimo dos íons dissolvidos na água é explicado pela renovação de água nos viveiros e o máximo pode ser pelo fato do aumento da matéria orgânica na água ser provenientes de excretas dos peixes e resto de ração não consumida, contribuindo para o aumento de íons nos viveiros (Ituassú et al., 2004).

O valor mediano da condutividade elétrica , encontra-se dentro do limite estabelecido por Zimermann et al., 2001 para criação de peixes que está na faixa de 20 a $150 \mu \mathrm{S} . \mathrm{cm}^{-1}$. Valores próximos encontrados por Pereira Junior et al.,(2013), na composição corporal do tambaqui alimentados com rações contendo farinha de folha de Leucena com valores médios de $23 \mu \mathrm{S} . \mathrm{cm}^{-1}$, por Guimarães \& Storti Filho (2004), no desempenho do tambaqui no policultivo com Jaraqui (Semaprochilodus insignis), alimentados com produtos agrícolas e florestais como suplementos (valor mínimo encontrado foi de $21,2 \mu$ S.cm $\left.{ }^{-1}\right)$.

A correlação positiva entre a condutividade elétrica e os sólidos totais dissolvidos (STD) era esperada, visto que, os STD é composto por substâncias inorgânicas e orgânicas presentes no meio. Por outro lado, a relação negativa entre a CE e o peso e o comprimento do animal, pode ser relacionada ao processo de calagem realizado no início do cultivo, o que favoreceu o aumento de íons dissolvidos no viveiro. Silva \& Fujimoto,2015também relacionaram o aumento da CE ao processo da calagem, utilizado em tanques-rede, durante o crescimento de tambaqui.

Os valores de $\mathrm{pH}$ detectados entre 5,57 a 7,78, ambos no período chuvoso, refletem características da região Amazônica, com o valor da mediana de 7,05 (Tabela I), valor considerado dentro da faixa confortável para o cultivo desta espécime. De acordo com Silva et al., (2008) o tambaqui apresenta resistência a água ácida e isso reflete sua ocorrência em ambientes naturalmente ácidos como as águas da bacia amazônica.

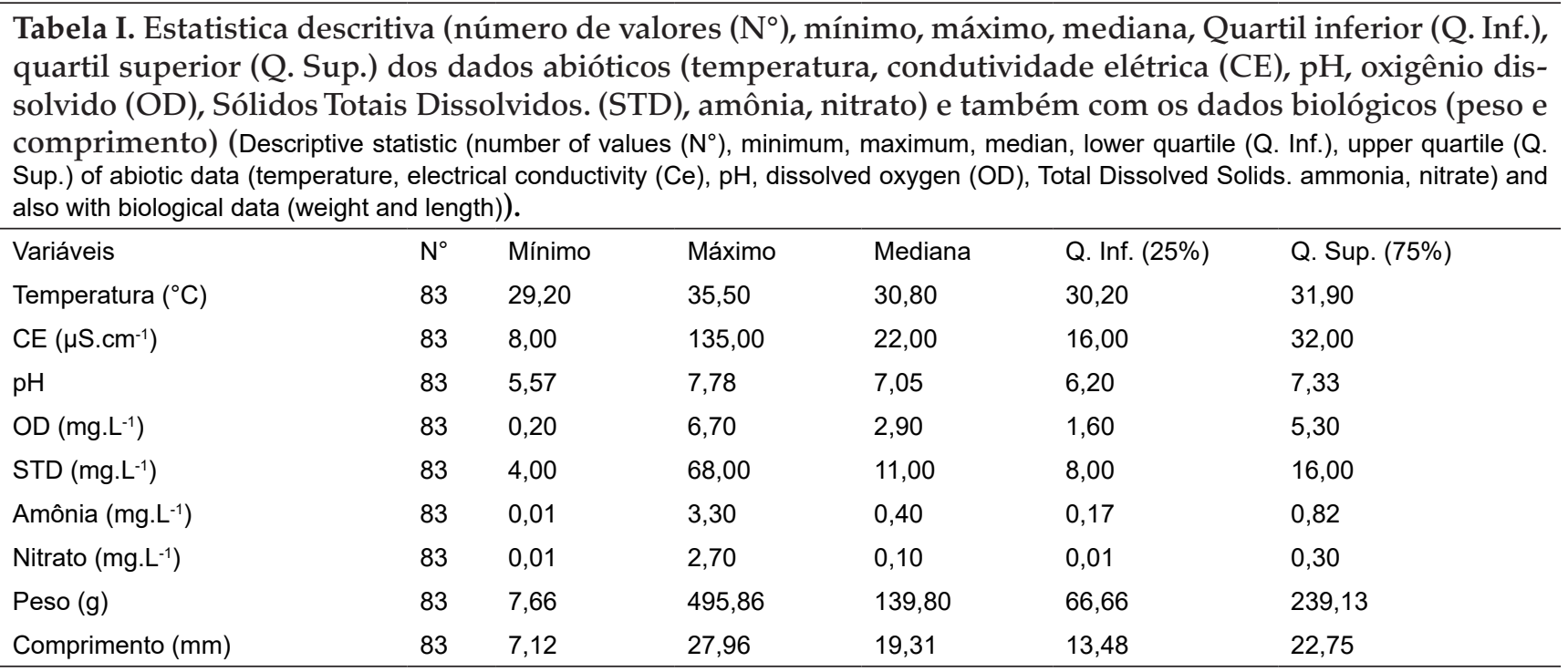


A sazonalidade teve uma influência negativa no $\mathrm{pH}$, como a incidência da chuva ocorreu principalmente no início do cultivo fazendo com que tivesse uma diminuição do $\mathrm{pH}$, com isto essa relação está ligada a menor temperatura da água no inverno, favorecendo a dissolução do oxigênio na água e a redução da atividade metabólica no sistema aquático que libera menos quantidade de gás carbônico para o meio, diminuindo a acidificação na água (Carmouze, 1994).

O oxigênio dissolvido oscilou 0,2 a $6,7 \mathrm{mg} . \mathrm{L}^{-1}$, no período seco e chuvoso respectivamente. $\mathrm{O}$ menor valor é resultante da alta taxa metabólica dos peixes nos tanques devido ao desempenho zootécnico no que refere-se ao ganho de peso e comprimento indicado no fim do experimento e outro condicionante pode ser explicado pela elevação da temperatura reduzindo a solubilidade do gás na água (Esteves, 1998), e também pode estar relacionado a decomposição da matéria orgânica decorrente das excretas e resto de ração.

O maior valor do oxigênio dissolvido indica o início do experimento onde os peixes estão pequenos e não há um grande consumo de oxigênio dissolvido nos viveiros.Segundo Araújo-Lima e Gomes (2005), o tambaqui tem seu crescimento normal em níveis de oxigênio acima de $3 \mathrm{mg} / \mathrm{L}$, então no presente estudo a faixa do oxigênio dissolvido estão abaixo do limite mínimo para a criação do tambaqui, pois nesta situação a hipóxia, baixo teor de oxigênio dissolvido na água, o tambaqui apresenta uma adaptação morfológica, o aumento do lábio inferior, que garante sua sobrevivência e também costuma nadar próximo à superfície para captar mais oxigênio, além de reduzir seu metabolismo e sua taxa de crescimento (Almeida-Val \& VAL, 1995).

Durante o processo de engorda do tambaqui sem renovação de água, formam constatados valores de oxigênio dissolvido entre 0,2 a $6,5 \mathrm{mg} \cdot \mathrm{L}^{-1}$, que mesmo próximo as condições de anoxia não formam observados mortalidades. Em um trabalho encontrados por Barroncas et al. (2015), observou-se valores diferentes oscilando 6,63 a 10,54 mg. $\mathrm{L}^{-1}$, Mendonça et al. (2009) encontrou valor médio de 5,75 mg. $\mathrm{L}^{-1}$ de oxigênio dissolvido na influência do fotoperíodo no desenvolvimento de tambaqui.

O oxigênio dissolvido teve correlação negativa com o peso e comprimento (Tabela II), indicando novamente a questão da alta taxa metabólica exercida pelos tambaquis nos tanques no decorrer do fim do experimento. Com a mediana de $2,9 \mathrm{mg} \cdot \mathrm{L}^{-1}$.

Os sólidos totais dissolvidos (STD) variou de 4 a $68 \mathrm{mg} . \mathrm{L}^{-1}$ no período seco e chuvoso respectivamente (Tabela I). O menor e maior valor são explicados pela sazonalidade, pois o que acarretou no aumento dos STD fui justamente a entrada de água no viveiro através da lixiviação decorrente as chuvas torrenciais tanto a possível falta de cobertura vegetal ao redor dos viveiros quanto na água abastecimento dos mesmo que eram realizados na preamar, e outro fator é a presença de alimentos não consumidos e excretas dos peixes, que são contribuintes mas expressivos para a carga de poluentes sob forma de matéria orgânica e os sólidos em suspenção (Beveridge et al. 1997).

Pois desta forma os STD são representados pela matéria orgânica dissolvida, matéria orgânica particulada e substâncias particuladas em suspenção (Beveridge et al. 1997), onde os dois fatores citados acima podem ser o motivo dos valores de STD. Segundo (Wedemeyer, 1997), a faixa ideal para cultivo de peixes de água doce está entre 5 a $200 \mathrm{mg} . \mathrm{L}^{-1}$, desta forma o valor da mediana (11 mg. $\left.\mathrm{L}^{-1}\right)$ encontra-se dentro da faixa permitida.

Os STD teve correlação negativa com o peso e comprimento (Tabela II) isto pode ser explicado a medida que o os peixes cresceram a quantidade de STD nos viveiros aumentaram decorrente ao acumulo matéria orgânica e material em suspensão na água referindo-se a quantidade excessiva de resto de ração, excreta e metabolitos da respiração dos tambaquis.

A amônia variou de 0,01 a $3,3 \mathrm{mg} \cdot \mathrm{L}^{-1}$, ambos valores no período chuvoso (Tabela I). O menor valor pode ser

Tabela II. Valores da Correlação de Spearman com as variáveis dos tratamentos, sazonalidade, abióticas (temperatura (Temp.), condutividade elétrica (CE), pH, Oxigênio Dissolvido (OD), Sólidos Totais Dissolvidos (STD), amônia, nitrato), parâmetros biológicos (Peso e Comprimento (Comp.)) (Spearman correlation values with treatment variables, seasonality, abiotic (temperature (Temp.), electrical conductivity (CE), pH, Dissolved Oxygen (OD), Total Dissolved Solids (STD), ammonia, nitrate), biological parameters (Weight and Length (Comp.))).

\begin{tabular}{|c|c|c|c|c|c|c|c|c|c|c|c|}
\hline Variáveis & Tratamentos & Temp. & CE & $\mathrm{pH}$ & OD & STD & Amônia & Nitrato & Peso & Comp. & Sazonalidade \\
\hline Tratamentos & 1,00 & & & & & & & & & & \\
\hline Temperatura & 0,26 & 1,00 & & & & & & & & & \\
\hline CE & $-0,12$ & 0,12 & 1,00 & & & & & & & & \\
\hline $\mathrm{pH}$ & $-0,06$ & $-0,14$ & $-0,10$ & 1,00 & & & & & & & \\
\hline OD & 0,03 & $0,57^{*}$ & 0,30 & $-0,12$ & 1,00 & & & & & & \\
\hline STD & $-0,12$ & 0,12 & $0,99^{*}$ & $-0,10$ & 0,30 & 1,00 & & & & & \\
\hline Amônia & $-0,09$ & $-0,17$ & $-0,02$ & $-0,17$ & $-0,12$ & $-0,01$ & 1,00 & & & & \\
\hline Nitrato & $-0,05$ & 0,18 & 0,03 & $-0,17$ & 0,12 & 0,00 & 0,04 & 1,00 & & & \\
\hline Peso & $-0,22$ & $-0,39$ & $-0,40^{*}$ & $-0,27$ & $-0,51^{*}$ & $-0,40^{*}$ & $-0,03$ & $-0,21$ & 1,00 & & \\
\hline Comp. & $-0,23$ & $-0,38$ & $-0,41^{*}$ & 0,25 & $-0,50^{*}$ & $-0,42^{*}$ & $-0,06$ & $-0,20$ & $0,96^{*}$ & 1,00 & \\
\hline Sazonalidade & $-0,08$ & $-0,14$ & $-0,24$ & $-0,47^{*}$ & $-0,19$ & $-0,26$ & $-0,12$ & $-0,17$ & $0,60^{*}$ & $0,59^{*}$ & 1,00 \\
\hline
\end{tabular}


explicado pelo fato de ter ocorrido a renovação de água no viveiro conforme a maré, por outro lado o maior valor indica o aumento da quantidades de metabólicos dissolvidos na água fazendo com que aumente a decomposição da matéria orgânica tais como quantidade de ração não consumida e excreta dos animais, por processo de respiração microbiana e nitrificação (Macedo \& Sipaúba-Tavares, 2010; Jamu \& Piedrahita, 2002).

O valor mediano da amônia total no presente estudo foi de $0,40 \mathrm{mg} . \mathrm{L}^{-1}$ (Tabela I), desta forma foi constatado dentro dos limites descritos por Chagas et al. (2007), na criação de tambaqui em tanques-rede em diferentes taxas de alimentação. No entanto, Bastos (2003), cita que várias espécies de peixes apresentam tolerância nos diversos estágios de vida apresentam tolerância variada em relação às diversas formas de nitrogênio, sendo letal uma concentração de amônia entre 0,6 a $2,0 \mathrm{mg} / \mathrm{L}$.

Valores próximos encontrados na criação de tambaqui em canais de abastecimento $\left(0,30 \mathrm{mg} . \mathrm{L}^{-1}\right)$,na determinação da melhor taxa e frequência de alimentação do tambaqui criados em tanques redes durante a fase inicial $\left(0,26 \pm 0,17 \mathrm{mg} . \mathrm{L}^{-1}\right)$, e outro estudo avaliando os efeitos de três óleos sobre os parâmetros de crescimento, composição corporal e capacidade comportamental do tambaqui $\left(0,24 \pm 0,20 \mathrm{mg} \cdot \mathrm{L}^{-1}\right)$, descrito por Silva et al. (2013), Silva et al. (2007) (Silva, Gomes \& Brandão 2007) e Pereira et al. (2018)(Pereira et al. 2018) respecitvamente.

O comportamento do nitrato nos viverios oscilou de 0,01 a 2,7 mg. $\mathrm{L}^{-1}$ no mesmo período da amônia (Tabela I). Isto pode ser explicado pelo fato que a amônia excretada pelos organismos aquáticos é oxidada em nitrato pela ação das bactérias quimioautotróficas ( $\mathrm{Ni}$ trosomonase Nitrobacter), que transformam $\mathrm{NH}_{4}^{+} \mathrm{em}$ $\mathrm{NO}_{2}^{-}$(nitrito) e $\mathrm{NO}_{2}^{-}$em $\mathrm{NO}_{3}^{-}$(nitrato) (Vinátea Arana, 1997). Desta forma o ambiente nos viveiros apresentou uma alta quantidade de oxigênio dissolvido no período chuvoso $\left(6,7 \mathrm{mgL}^{-1}\right)$, com isso propiciou a transformação da amônia em nitrato pois, segundo Esteves (1998), referindo-se ao $\mathrm{NH}_{4}^{+}$, diz que para oxidar $1,0 \mathrm{mg}$ desse íon são necessários cerca de $4,3 \mathrm{mg}$ de $\mathrm{O}_{2}$. Por isso o $\mathrm{NH}_{4}{ }^{+}$tem fortes implicações ecológicas, pois influencia a comunidade de peixes.

O valor do nitrato tolerável para cultivo de peixes é de até $5 \mathrm{mg} \mathrm{L}^{-1}$ (Sipaúba-Tavares, 1995), no entanto acima deste mesmo pode ser um composto importante para a aquicultura, quando em altas concentrações, afeta negativamente o metabolismo dos animais cultivados (Vinátea Arana, 2004). Com isso os valores de nitrato no presente trabalho encontram-se dentro do limite.

Valores próximos encontrados na qualidade da água em uma piscicultura em tanque-rede no reservatório de ilha solteira São Paulo encontrou $\left(2,01 \mathrm{mg} . \mathrm{L}^{-1}\right)$, valores próximos encontrados em analises da qualidade da água em tanques de piscicultura no município de Rolim de Moura - RO (2,05 mg. $\left.\mathrm{L}^{-1}\right)$, e valores próximos a este presente trabalho encontrado no levantamento de dados da qualidade da água dos cultivos de tambaqui no município de Rio Preto - AM, descritos nos trabalhos de Mallasen et al. (2012) Stachiw et al. (2013) Freitas et al. (2014) respectivamente.

O peso oscilou 7,66 a $495 \mathrm{~mm}$ o comprimento de 7,12 a 27,96 cm no início do cultivo (período chuvoso) até o fim do experimento (período seco), para ambos dados biométricos justificando o início do experimento com a entrada dos indivíduos jovens até a finalização com os peixes maiores.

Na análise de componentes principais com os parâmetros físicos-químicos da qualidade da água nos viveiros, com o peso e comprimento (tratamentos mais o controle) e a sazonalidade desta forma, as duas componentes (PC1 e PC2) juntas descrevem cerca de 55\% da variância original (Figura 2.A). A PC1 explicou 35\% de variância total, onde o lado superior direito quem respondeu foi a temperatura $(0,50)$, oxigênio dissolvido $(0,64)$ e nitrato $(0,41)$ na parte inferior a condutividade elétrica $(0,40)$ e sólidos totais dissolvidos $(0,38)$ e no lado esquerdo somente na parte inferior foram o $\mathrm{pH}$ $(-0,47)$, a sazonalidade $(-0,70)$, comprimento $(-0,87)$ e o peso $(-0,91)$. A PC2 explicou $20 \%$ onde os que apenas tiveram representatividade foram temperatura $(0,50)$, Condutividade elétrica $(0,90)$ e sólidos totais dissolvidos $(-0,90)$.

Os escores para os dados da qualidade da água nos viveiros em PC1 e PC2, estratificado de acordo com sazonalidade observou-se uma separação nítida indicando uma diferença significativa do lado esquerdo em relação ao lado direito no período cedo e chuvoso respectivamente (Figura 2.B). E os escores para os dados dos percentuais dos tratamentos (ração comercial mais a massa de mandioca) e o controle constatou-se que não houve diferença entre eles, afirmando com o correlação de Spearman (Figura 2.C).

\section{CONCLUSÃO}

Os tratamentos empregados não tiveram uma influência no crescimento do peixe e nem na qualidade

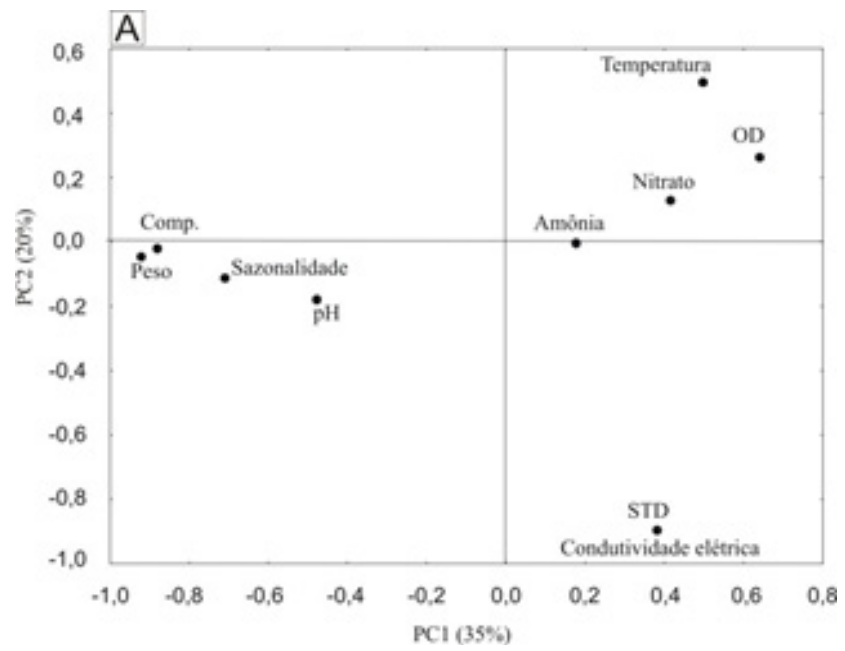

Figura 2A. Análise de componentes principais dos parâmetros abióticos, do peso e do comprimento do peixe durante o período de sazonalidade (Analysis of the main components of the abiotic parameters, weight and length of the fish during the seasonality period). 

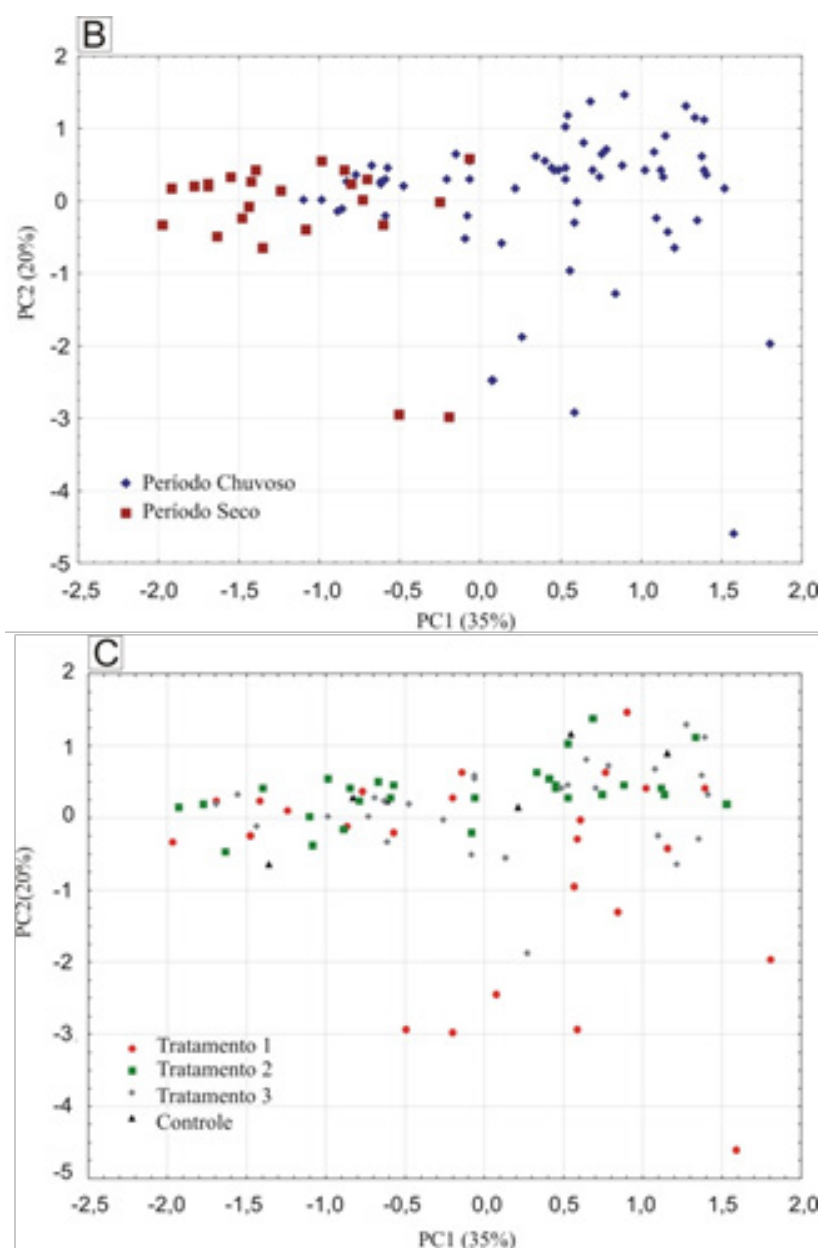

Figura 2B, C. (B) Parâmetros abióticos em relação a sazonalidade; (C) Parâmetros zootécnicos em relação aos tratamentos e controle ((B) Abiotic parameters in relation to seasonality; (C) Zootechnical parameters in relation to treatments and control).

da água, sendo uma alternativa para diminuir os custos em locais rurais. A variável com maior destaque foi à sazonalidade da região. Os dados dos parâmetros físicos e químicos, como a temperatura, o oxigênio dissolvido, $\mathrm{CE}$ e o $\mathrm{pH}$ tiveram uma relação com o desenvolvimento dos peixes. Os compostos nitrogenados não tiveram nem uma modificação ao longo do desenvolvimento e não influenciaram no desenvolvimento do peixe, o que pode ser relacionado com as trocas de água necessárias durante a criação dos mesmos.

\section{BIBLIOGRAFÍA}

Almeida-Val, VMF \& VAL, ALA 1995, 'A adaptação de peixes aos ambientes de criação.', in Criando peixes na Amazônia., INPA, Manaus. Araújo-Lima, CARM \& Gomes, LC 2010, 'Espécies nativas para piscicultura no Brasil.', in Tambaqui (Colossoma macropomum), 2nd edn, UFSM, Santa Maria.

Arbeláez-Rojas, GA, Fracalossi, DM \& Indrusiak Fim, JD 2002, 'Composição Corporal de Tambaqui, Colossoma macropomum, e Matrinxã, Brycon cephalus, em Sistemas de Cultivo Intensivo, em lgarapé, e Semi-Intensivo, em Viveiros', Revista Brasileira Zootecnia, vol 31, no. 3, pp. 1059-1069.

Barroncas, M, Pereira-Filho, M, Gomes, LD, Roubach, R \& Ono, E 2015, 'Efeitos da troca de água sobre os índices zootécnicos e qualidade dos efluentes na criação intensiva do tambaqui (Colossoma macropomum) em viveiros escavados', Revista Brasileira Engenharia Pesca, vol 8, no. 1, pp. 49-71.

Bastos, RKX 2003, Utilização de Esgotos Tratados em Fertirrigação, Hidroponia e Piscicultura, PROSAB, Rio de Janeiro.

Bernardino, G \& Melo, JSC 1989, 'Estimativa do tamanho mínimo da amostra do pacu Piaractus mesopotamicusHolmberg, 1887, em monocultura em viveiros experimentais', Boletim Técnico CEPTA, vol 2, pp. 75-89.

Beveridge, MCM, Phillips, MJ \& Macintosh, DJ 1997, 'Aquaculture and the environmente: supply of and demand fpr environmental goods and service by Asian aquiculture and the implications for sustainability.', Aquiculture Research., vol 28, pp. 797-807.

Carmouze, JP 1994, O metabolismo dos ecossistemas aquáticos: fundamentos teóricos, métodos de estudo e análises químicas., Edgar Blücher Ltda/Fundação de Amparo à Pesquisa do Estado de São Paulo, São Paulo.

Chagas, E, Gomes, L, Martins Júnior, H \& Roubach, R 2007, 'Produtividade de tambaqui criado em tanque-rede com diferentes taxas de alimentação.', Ciência Rural, vol 37, pp. 1109-1115.

Cyrino, JE, Bicudo, ÁJA, Borghesi, R \& Dairik, KJ 2010, 'A piscicultura e o ambiente - o uso de alimentos ambientalmente corretos em piscicultura', Revista da Sociedade Brasileira de Zootecnia, vol 39, pp. 68-87.

Esteves, FA 1998., Fundamentos de Limnologia., 2nd edn, Interciência., Rio de Janeiro..

Freitas, RS, Boijink, CL, Muniz, AW, Dairiki, JK \& Inove, LAKA 2014, 'Qualidade da água e perspectivas para gerenciamento ambiental dos cultivos de tambaqui no município de Rio Preto da Eva, AM', Scientia Amazonia, vol 3, no. 1, pp. 116-126.

Galdioli, EM, Hayashi, C, Soares, CM, Furuya, VRB \& Faria, ACA 2002, 'Substituição da Proteína do Farelo de Soja pela Proteína do Farelo de Canola em Rações para Alevinos de Curimbatá (Prochilodus lineatus V.)', Revista Brasileira de Zootecnia, vol 31, no. 2, pp. 552-559.

Guimarães, SF \& Storti Filho, A 2004, 'Produtos agrícolas e florestais como alimento suplementar e tambaqui em policultivo com jaraqui', Pesquisa Agropecuaria Brasileira, vol 39, no. 3, pp. 293-296.

Ituassú, DR, Santos, GRS, Roubach, R \& Pereira-Filho, 2004, 'Desenvolvimento de tambaqui submetido a períodos', Pesquisa Agropecuaria Brasileira, vol 39, no. 12, pp. 1199-1203.

Jamu, DM \& Piedrahita, RH 2002, Na organic matter and nitrogen dynamics model for the ecological analysis of integrated auqculture/ agricultire sustems: I model devolopment and calibration.', Environmental Modeling, vol 17, pp. 571-582.

Kubitza, F 2003, Qualidade da Água no Cultivo de Peixes e Camarões, 1 st edn, Jundiaí.

Macedo, CF \& Sipaúba-Tavares, LH 2010, ' Eutrofização e qualidade da água na piscicultura: consequências e recomendações.', Boletim do Instituto de Pesca, vol 36, no. 2, pp. 149-163.

Mallasen, M, Carmo, CF, TUCCI, A, Barros, HP, Rojas, NET, Fonseca, FS \& Yamashita, EY 2012, 'Qualidade da água em sistema de piscicultura em tanques-redes no reservatório de llha Solteira, SP', Boletim do Instituto de Pesca, vol 38, no. 1, pp. $15-30$.

Mendonça, PP, Costa, PC, Polese, MF, Vidal Junior, MV \& Andrade, DR 2012, 'Efeito da suplementação de fitase na aliemnatçãode juvenis de tambaqui (Colossoma macropomum).', Archivos de Zootecnia , vol 61, pp. 437-448.

Pereira Junior, G, Barbosa, PS, Shimoda, E \& Pereira Filho, M 2013 'Composição corporal de tambaqui alimentado com rações contendo farinha de folha de Lucena', Archivos de Zootecnia, vol 62, no. 238, pp. 211-216.

Pereira, LPF \& Mercante, CTJ 2005, 'A amônia nos sistemas de criação de peixes e seus efeitos sobre a qualidade da água. Uma revisão.', Boletim do Instituto de Pesca, vol 31, pp. 81-85.

Pereira, RT, Paulino, RR, Almeida, CAL, Rosa, PV, Orlando, TM \& FortesSilva, R 2018, 'Oil sources administered to tambaqui (Colossoma macropomum): growth, body composition and effect of masking organoleptic properties and fasting on diet preference', Applied Animal Behaviour Science, vol 199, pp. 103-110. 
Sá, MVDC \& Fracalossi, DM 2002, 'Exigência Protéica e Relação Energia/ Proteína para Alevinos de Piracanjuba (Brycon orbignyanus)', Revista Brasileira de Zootecnia, vol 31, no. 1, pp. 1-10.

Santos, VA, Lourenço, CB, Malcher, CS, Trindade, GV, De Araújo, RF \& Lobão, RA 2015, 'Relação peso-comprimento e fator de condição relativo do tambaqui, Colossoma macropomum(Cuvier, 1818) em cativeiro utilizando amassa de mandioca como alimento alternativo.', Boletim Técnico Cientifico do CEPNOR, vol 15, no. 1, pp. 09-13.

Silva, AEP, Angelis, CF, Machado, LAT \& Waichaman, AV 2008, 'Influência da precipitação na qualidade da água do Rio Purus', Acta Amazonica, vol 38, pp. 733-742.

Silva, CA \& Carneiro, PCF 2007, 'Qualidade da água na engorda de tambaqui em viveiros sem renovação da água.', Folders, 2007.

Silva, CA \& Fujimoto, RY 2015, 'Crescimento de tambaqui em resposta a densidade de estocagem em tanques-rede.', Acta Amazonica, vol 45 , no. 3, pp. 323 - 332.

Silva, CR, Gomes, LC \& Brandão, FR 2007, 'Effect of feeding rate and frequency on tambaqui (Colossoma macropomum) growth, production and feeding costs during the first growth phase in cages', Aquaculture, vol 264, pp. 135-139.

Silva, JAM, Pereira-Filho, M \& Oliveira-Pereira, MI 2003, 'Frutos e sementes consumidos pelo tambaqui, Colossoma macropomum (Cuvier, 1818) incorporados em rações. Digestibilidade e velocidade de transito pelo trato gastrointestinal', Revista Brasileira de Zootecnia, vol 32, no. 2, pp. 2-12.

Silva, A, Santos, R, Bruno, A \& Soares, E 2013, 'Cultivo de tambaqui em canais de abastecimento sob diferentes densidades de peixes', Acta Amazonica, vol 43, no. 4, pp. 517 - 524.

Sipaúba-Tavares, LH 1995, Limnologia aplicada à aquicultura, FUNEP, Jaboticabal.

Soares, CM, Hayashi, C, Faria, ACEA \& Furuya, WM 2001, 'Substituição da Proteína do Farelo de Soja pela Proteína do Farelo de Canola em dietas para a tilápia do nilo (Oreochrmis niloticus) na fase de crescimento', Revista Brasileira de Zootecnia, vol 30, no. 4, pp. 1172-1177.
Soares, CM, Hayashi, C, Furuya, VRB, Furuya, WM \& Galdioli, EM 2000, 'Substituição parcial e total da proteína do farelo de canola na alimentação de alevinos de piavuçu (Leporinus macrocephalus, L.)', Revista Brasileira de Zootecnia, vol 29, no. 1, pp. 5-22.

Stachiw, R, Silva, FR, Vendruscolo, J, Medeiros, TF, Tavares, VCC \& Dutra, AR 2013, 'Qualidade da água de taques de piscicultura em Rolim de Moura-RO', Revista Brasileira de Ciências da Amazônia, vol 2, no. 1, pp. 22-34.

Val, AL \& Honczaryk, A 1995, 'A adaptação de peixes aos ambientes de criação', in Criando peixes na Amazônia, INPA, Manaus.

Vidal Junior, MV, Dozele, JL, Andrade , DR \& Santos, LC 2004, 'Determinação da digestibilidade da matéria seca e da proteína bruta do fubá de milho e do farelo de soja para tambaqui (Colossoma macropomun), tutilizando-se técnicas com o uso de indicaderes internos e externos', Revista Brasileira de Zootecnia, vol 33, no. 6, pp. 2193-2200.

Vieira, JS, Logato, RPV, Ribeiro, PAP, De Freitas, RTF \& Fialho, ET 2005, 'Efeito do processamento do milho sobre o desempenho e compisição de Carcaça de piaba (Leporinus friderici) criada em tanques-rede', Ciências agrotécnicas, vol 29, no. 2, pp. 453-458.

Vinátea Arana, L 1997, Princípios Químicos de Qualidade da Água em Aqüicultura: uma revisão para peixes e camarões, UFSC, Florianópolis/SC.

Vinátea Arana, L 2004, Princípios químicos de qualidade da água em aquicultura: uma revisão para peixes e camarões, 2nd edn, UFSC, Florianópolis/SC.

Von Sperling, M 2007, Estudos de modelagem da qualidade da água de rios., UFMG, Belo Horizonte.

Wedemeyer, GA 1997, 'Fish stress and health in aquaculture. ', in Effects of rearing conditions on the Health and physiological quality of fish in Intensive culture., Cambridge University Press, United Kingdom.

Zimermann, S, Ribeiro, RP, Vargas, L\&Momeira, HLM 2001, Fundamentos da moderna aquicultura, ULBRA, Canoas. 